\title{
University Website Quality Ranking using Logarithmic Fuzzy Preference Programming
}

\author{
Retantyo Wardoyo ${ }^{1}$, Tenia Wahyuningrum ${ }^{2}$ \\ ${ }^{1}$ Department of Computer Science and Electronics, Universitas Gadjah Mada, Yogyakarta, Indonesia \\ ${ }^{2}$ Department of Informatics, IT Telkom Purwokerto, Indonesia
}

\begin{tabular}{l} 
Article Info \\
\hline Article history: \\
Received Dec 8, 2017 \\
Revised Feb 19, 2018 \\
Accepted Mar 7, 2018 \\
\hline
\end{tabular}

Keyword:

Logarithmic fuzzy preference Programming University website Website quality

\begin{abstract}
The current tight competition in developing University websites forces developers to create better products that meet users needs and convinient. There are at least two factors representing university websites; accessibility and usability. We test three criteria of accessibility and usability that are called stickiness, backlink, and web page loading time. Usability and accessibility are closely related to subjective user judgments. Human judgment cannot be valid. Thus the use of fuzzy numbers are expected to provide solutions in calculating the results. In this research, the question of usability is a multi criteria decision-making problem that is caused by its complex structure. We use the Logarithmic Fuzzy Preference Programming (LFPP) method, which is a refinement of the Fuzzy Analytical Hierarchy Process method, to solve this problem. This research aims to re- assess the rank of five Indonesian university websites. Based on LFPP method, we obtain that the equation of model gets high consistency of the set priority matching to fuzzy pairwise comparison matrix of three selection criteria. The calculation results show that stickiness is the most significant factor that affects the quality of the websites.
\end{abstract}

Copyright $(2018$ Institute of Advanced Engineering and Science. All rights reserved.

\section{Corresponding Author:}

Tenia Wahyuningrum, Departement of Informatics, Institut Teknologi Telkom,

Jl. DI Panjaitan 128, Purwokerto, Indonesia.

Email: tenia@ittelkom-pwt.ac.id

\section{INTRODUCTION}

University website reflects the university's academic activities. Thus, the more qualified a university, the more qualified its website. Some researchers discuss the variety of college sites based on its performance. However, there is lack one to another [1]-[3]. They examine the characteristics used for the assessment, then do the website ranking. The most ratings used to represented quality are Webometrics Ranking of World Universities, uniRank ${ }^{\mathrm{TM}}$ (formerly 4 International Colleges \& Universities or 4ICU.org), and eduroute. Webometrics ranking consists of four criteria such as visibility, size, rich files and scholar [4]. The uniRank $^{\mathrm{TM}}$ ranking methodology used five indicators from four different web intelligence (Moz domain authority, Alexa Global Rank, SimilarWeb global rank and Majestic) [5]. Eduroute ranking methodology consists of four criteria, there are volume, links quantity, quality of links and content, and online scientific Information. The disadvantage of webometrics methods is only suitable for universities with a high commitment to publication. While uniRank ${ }^{\mathrm{TM}}$ and eduroute just focus on the popularity of the websites.

Based on some university ranking shortcomings, We tried to look at website quality based on different perceptions. One of the research on website quality shows that website quality evaluation criteria focus on usability and accessibility [1]. Accessibility is a level of scope of users to achieve certain goals [6], [7]. Meanwhile, usability covers the simplicity in learning, effectiveness, and pleasure for the users [6], [8]-[11]. The factors affected accessibility and usability represented by load time, stickiness, and backlink. 
The experiments performed by Dominic and Hanim (2013) used Fuzzy AHP with Extent Analysis (EA) methods on the quality of university websites in Malaysia based on usability criteria [1]. The deficiency of most FAHP applications using the EA method proposed by Chang (1996) is considered invalid and the weight obtained by this method does not represent the relative importance of the criterion or decision criteria [12]-[16]. To address the deficiencies of the FAHP method with EA, then Mikhailov (2004) proposed the Fuzzy Preference Programming (FPP) method to derived the crisp weight of the pairwise matrix comparison [17]. Nevertheless, there are some shortcomings of FPP methods proposed by Mikhailov (2004). The lack of the FPP method are (1) Negative membership degree makes no sense, (2) FPP model produces multiple optimal solutions when there exists strong inconsistency among the fuzzy judgments, (3) The priority vectors derived by using the upper or lower triangular elements of a fuzzy pairwise comparison matrix are not the same, even significantly different [18].

The non linear based Logarithmic Fuzzy Preference Programming (LFPP) is the improved FPP that aims to resolve the negative membership degree result and multiple optimal solutions when there exists significant inconsistency among the fuzzy judgments [18]. This method uses logarithmic elements of natural numbers that can produce a single solution in determining the value of importance weights. This research has been integrating LFPP method to rank the quality of University websites. By using this method, it is expected that quality ranking of University website can be made better. This paper is organized as follows. Section 2 discusses literature study; Section 3 describes the result and discussion, and Section 4 presents the conclusions and suggests some areas for further investigation.

\section{LITERATURE STUDY}

\subsection{University website rank}

Some studies create a method to measure the quality of university websites, such as webometric, uniRank $^{\mathrm{TM}}$ and eduroute. Table 1 summarizes the university website quality ranking methodology.

Table 1. Methodology

\begin{tabular}{llll}
\hline Criteria & \multicolumn{1}{c}{ Webometrics } & \multicolumn{1}{c}{ Unirank } & Eduroute \\
\hline First Release & 2004 & 2005 & 2011 \\
URL Web & http://www.webometrics.info & http://www.4icu.org/ & 1000 \\
Univ's analyzed & 16000 & 13000 & 500 \\
Univ's ranked & $5000+$ & 200 & Volume $(20 \%)$ \\
Size & Web size $(20 \%)$ & & Online Scientific information \\
Research output & Rich Files (15\%) & & $(10 \%)$ \\
& Google Scholar (15\%) & & Links quantity (30\%), \\
Impact & (Link) Visibility (50\%) & Majestic Reffering Domains, & Quality of links and content \\
& & Majestic Trust Flow, & $(20 \%)$ \\
& & Alexa Global Rank, & Similar web Global Rank, \\
& & Moz domain authority & \\
\end{tabular}

Isidro and the research group from Cybermetrics Lab, Spain, initiate university web ranking based on four criteria called webometrics. Since 2004, every six months, they released the rank based on web presence and impact. Webometrics analyzes 16.000 universities from various place in the world and ranks over 5.000 universities. Webometrics uses google, google scholar, Majestic SEO and ahrefs website tools to retrieve the data [4]. In 2005, the uniRank ${ }^{\mathrm{TM}}$ University Ranking from Australia launched a relative popularity ranking of world Universities and Colleges based on the popularity of their websites regarding traffic, trust and quality link popularity [19]. The uniRank position supports the international students and teachers to understand the university popularity in a foreign country. Eduroute released the university web ranking in 2011 but it did not continue until now. Eduroute focuses on studying and evaluating school websites based on volume, links quantity, quality of links and content, and online scientific information [20].

The uniRank ${ }^{\mathrm{TM}}$ and eduroute use the popularity of websites to rank. The uniRank ${ }^{\mathrm{TM}}$ and eduroute lead to their method of having full dependence on search engine algorithms. Unfortunately, we do not know exactly how the search engines work. Search engine developers hide their algorithms in indexing or crawling websites [21]. Webometrics studies the building and using information resources, web structures and technologies with bibliometric and infometric approaches. Webometrics does not aim to evaluate web design, usability or popularity of contents against the number of visitors [22]. Meanwhile, uniRank ${ }^{\mathrm{TM}}$ also has one main weakness in which its judgment is developed based solely on the popularity and usage of the website 
only and does not see the content of the site. The disadvantages of eduroute rating are the unclear method of ranking calculation they have and the tools used for data collection. Based on the problems above, it is necessary to conduct further study in order to investigate the quality factor of university websites.

\subsection{Website quality study}

There are a lot of discussions about the factor quality of websites. Certain factor, such as performance, is important to evaluate [1], [5], [23]. A research on 71 Bangladeshi college websites reveals that the important criteria of web presence are the number of web page, simple web impact factor, self-link web impact factor and external link web impact factor [24]. Another study shows that based on web developer or administrator and user assessment, the websites performance factor represented by accessibility and usability [1].

The accessibility of a website can be represented by its response time. There are three responses of time limit; the first is 0.1 seconds limit that make the users think that the system react immediately. The second limit is 1.0 seconds that leads the usesrs thought stay for a while and interrupted. The ultimate limit is 10 seconds that keeps the users' attention focused on the dialogue. Amerson says that the average server response time must be less than $0.5 \mathrm{sec}$ [1], [23], [25].

Studies of website usability have shown that slow page rendering is typically caused by not big images. But also server delay (because of complex data processing) or overly fancy page widgets. The number of a component such as a widget, images, video and sounds that embedded to the websites are also the significant factor to be investigated [26].

The other criterion of site quality is its loading time. The quality standard of the web page loading time must be less than 30 seconds with average server response time must less than 0.5 seconds [27]. Loading time is time median required to load a web page on the browser of the users concretely.

Stickiness is a capability to ensure that each user has been stuck on a page of the website in the period of time. A pleasurable site will attract the users to revisit later emerging a positive impact that is traffic impact. A backlink is measured from the number of links referring to the main page. It shows the credibility of a website for being correlated to the prestige and popularity of a website [1], [5], [23]. Thus, this research test three criteria of accessibility and usability, namely stickiness, backlink, and web page loading time.

\subsection{Analytical hierarchy process (AHP)}

AHP is a decision support model developed by Thomas L. Saaty. This decision support model would describe multi-criteria problems into particular hierarchy. The first level of the hierarchy is the goal, which is followed by the level, criteria, sub-criteria, and so on down to the last stage of the alternative. With certain structure, a complex problem can be broken down into groups that are then organized into a hierarchical form so that the problem will seem more structured and systematic [28]. The AHP weakness lies in the use of unproportionate evaluation scales and is unable to handle the uncertainty of pairwise comparison processes [29]. Decision makers are usually involved in making the right choice in fixed judgment. They prefer to use interval sense to overcome the comparison process to be more accurate. The AHP method used a crisp number to represent human judgment. Along with the increased complexity of the problem, the researchers combine the concept of fuzzy logic with AHP which is known as Fuzzy Analytical Hierarchy Process (FAHP) [30], [31]-[36]. The number used is no longer the crisp number but the fuzzy number.

\subsection{Fuzzy number}

Chang [37] defined a fuzzy number $A$ on $R$ to be a triangular fuzzy number if its membership function $\mu_{A}(x): R \rightarrow[0,1]$ is equal to

$$
\mu_{A}(x)=\left\{\begin{array}{c}
\frac{(x-l)}{(m-l)}, x \in[l, m], \\
\frac{(u-x)}{(u-m)}, x \in[m, u], \\
0, \text { otherwise }
\end{array}\right.
$$

Where $l \leq m \leq u, l$ and $u$ stand for the lower and upper value of the support of $A$ respectively, and $\mathrm{m}$ for the modal value. The triangular fuzzy number (TFN) can be denoted by $(l, m, u)$. The membership function of TFN can be seen in Figure 1 [14], [15], [38]. 


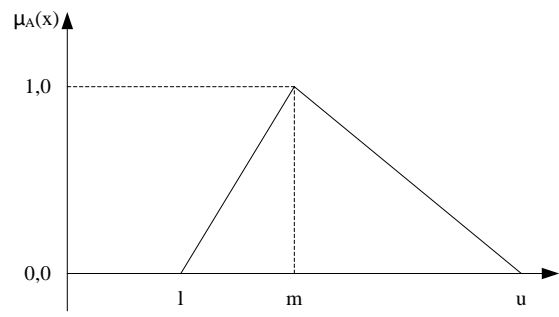

Figure 1. A Triangular Fuzzy Number of $A$

Consider two triangular fuzzy numbers $A_{1}$ and $A_{2}, A_{1}=\left(l_{1}, m_{1}, u_{1}\right)$, and $A_{2}=\left(l_{2}, m_{2}, u_{2}\right)$ then

$$
\begin{aligned}
& A_{1} \oplus A_{2}=\left(l_{1}, m_{1}, u_{1}\right) \oplus\left(l_{2}, m_{2}, u_{2}\right)=\left(l_{1}+l_{2}, m_{1}+m_{2}, u_{1}+u_{2}\right) \\
& A_{1} \otimes A_{2}=\left(l_{1}, m_{1}, u_{1}\right) \otimes\left(l_{2}, m_{2}, u_{2}\right)=\left(l_{1} \times l_{2}, m_{1} \times m_{2}, u_{1} \times u_{2}\right), l_{i}>0, m_{i}>0, u_{i}>0 \\
& A_{1}-A_{2}=\left(l_{1}, m_{1}, u_{1}\right)-\left(l_{2}, m_{2}, u_{2}\right)=\left(l_{1}-l_{2}, m_{1}-m_{2}, u_{1}-u_{2}\right) \\
& A_{1} \div A_{2}=\left(l_{1}, m_{1}, u_{1}\right) \div\left(l_{2}, m_{2}, u_{2}\right)=\left(l_{1} / l_{2}, m_{1} / m_{2}, u_{1} / u_{2}\right), l_{i}>0, m_{i}>0, u_{i}>0 \\
& A_{1}^{-1}=\left(l_{1}, m_{1}, u_{1}\right)=\left(1 / u_{1}, 1 / m_{1}, 1 / l_{1}\right), l_{i}>0, m_{i}>0, u_{i}>0
\end{aligned}
$$

We used the TFN to constructed fuzzy evaluation matrix on AHP method. If the strong importance of element $j$ over element $i$ holds, then the pairwise comparison scale can be represented by the fuzzy number $a_{i j}^{-1}=\left(\frac{1}{u}, \frac{1}{m}, \frac{1}{l}\right)$.

\subsection{Fuzzy linguistic variables}

Linguistic variables can be defined as a variable that represents different aspects of human language. It can be displayed by fuzzy numbers that suitable to constitute a degree of subjective judgment. Meanwhile, assessment weights are expressed in linguistic variables with values; "Very unimportant", "Unimportant", "Fair", "Important", "Very important" or "Very Poor", "Poor", "Fair", "Good", and "Very Good" [39]-[41].

\begin{tabular}{|c|c|}
\hline Convert from AHP scale to Fuzzy number & Linguistic expressions \\
\hline $1=(1,1,1)$ & Equal \\
\hline $2=(1,2,3)$ & Equal-moderate \\
\hline $3=(2,3,4)$ & Moderate \\
\hline $4=(3,4,5)$ & Moderate-fairly strong \\
\hline $5=(4,5,6)$ & Fairly strong \\
\hline $6=(5,6,7)$ & Fairly strong-very strong \\
\hline $7=(6,7,8)$ & Very strong \\
\hline $8=(7,8,9)$ & Very strong-absolute \\
\hline $9=(8,9,9)$ & Absolute \\
\hline $2,4,6,8$ & Values between two adjacent assessments \\
\hline
\end{tabular}
Table 2 shows the nine basic linguistic terms that are used in this research. Each membership function (scale of fuzzy number) is defined by three parameters of the symmetric triangular fuzzy number, the lower point, middle point, and upper point of the range over which the function is defined.

Table 2. Membership Function Linguistic Scale [23] 


\subsection{Logarithmic fuzzy preference programming}

Wang explained that LFPP method is a refinement of the FPP process. In FPP method, a few cases resulted in the final value of the negative course this makes the solution is expected to be less valid [18]. LFPP method involves a logarithmic function original to correct deficiencies FPP method.

We used a fuzzy numbers in the assessment in questionnaires by users who have knowledge of the issues to be tested, in this case, university website quality ranking. Then a fuzzy pairwise comparison matrix can be expressed as

$$
\tilde{A}=\left(\tilde{a}_{i j}\right)_{k \times k}=\left[\begin{array}{cccc}
1 & \left(l_{12}, m_{12}, u_{12}\right) & \cdots & \left(l_{1 k}, m_{1 k}, u_{1 k}\right) \\
\left(l_{21}, m_{21}, u_{21}\right) & 1 & \cdots & \left(l_{2 k}, m_{2 k}, u_{2 k}\right) \\
\vdots & \vdots & \ddots & \vdots \\
\left(l_{k 1}, m_{k 1}, u_{k 1}\right) & \left(l_{k 2}, m_{k 2}, u_{k 2}\right) & \cdots & 1
\end{array}\right]
$$

where

$$
l_{i j}=1 / u_{j i}, m_{i j}=1 / m_{j i}, u_{i j}=1 / l_{j i} \text { and } 0<l_{i j}<m_{i j}<u_{i j} \text { for all } i, j=1,2, \ldots, k, j \neq i(8)
$$

To find a crisp priority vector $W=\left(w_{1}, w_{2}, \ldots, w_{k}\right)^{T}>0$ with $\sum_{i=1}^{k} w_{i}=1$ for the fuzzy pairwise comparison matrix [18]. The approximate equation uses natural logarithmic numbers for the improvement of a paired matrix of fuzzy (7).

$$
\ln a_{i j} \approx\left(\ln l_{i j}, \ln m_{i j}, \ln u_{i j}\right), i, j=1,2, \ldots, k .
$$

The membership function of triangular fuzzy judgment can accordingly be defined as

$$
\mu_{i j}\left(\ln \left(w_{i} / w_{j}\right)\right)=\left\{\begin{array}{l}
\frac{\ln \left(w_{i} / w_{j}\right)-\ln l_{i j}}{\ln m_{i j}-\ln l_{i j}}, \ln \left(w_{i} / w_{j}\right) \leq \ln m_{i j}, \\
\frac{\ln u_{i j}-\ln \left(w_{i} / w_{j}\right)}{\ln u_{i j}-\ln m_{i j}}, \ln \left(w_{i} / w_{j}\right) \geq \ln m_{i j},
\end{array}\right.
$$

where $\mu_{i j}\left(\ln \left(w_{i} / w_{j}\right)\right)$ is the membership degree of $\ln \left(w_{i} / w_{j}\right)$ belonging to the approximate triangular fuzzy judgment $\ln a_{i j}=\ln \left(l_{i j}, m_{i j}, u_{i j}\right)$. To maximize the minimum membership degree, can be found by the crisp priority vector $\lambda=\min \left\{\mu_{i j}\left(\ln \left(w_{i} / w_{j}\right)\right) j i=1,2, \ldots, k-1 ; j=i+1, \ldots, k\right\}$. The resultan model can be constructed as

Maximize $\lambda$

Subject to $\left\{\begin{array}{c}\mu_{i j}\left(\ln \left(w_{i} / w_{j}\right)\right) \geq \lambda, i=1,2, \ldots, k-1 ; j=i+1, \ldots, k, \\ w_{i} \geq 0, i=1,2, \ldots, k,\end{array}\right.$

or as

Maximize $1-\lambda$

Subject to $\left\{\begin{array}{l}\ln w_{i}-\ln w_{j}-\lambda \ln \left(m_{i j} / l_{i j}\right) \geq \ln l_{i j}, i=1,2, \ldots, k-1 ; j=i+1, \ldots, k, \\ -\ln w_{i}+\ln w_{j}-\ln \left(u_{i j} / m_{i j}\right) \geq-\ln u_{i j}, i=1,2, \ldots, k-1 ; j=i+1, \ldots, k, \\ w_{i} \geq 0, i=1,2, \ldots k .\end{array}\right.$ 
The normalization constraint $\sum_{i=1}^{k} w_{i}=1$

is not included int the above two equivalent models. This is because the models will become computationally complicated if the normalization constraint is included. Before normalization, without loss of generality, can be assummed that $w_{i} \geq 1$ for all $i=1,2, \ldots k$ such that $\ln w_{i} \geq 0$ for $i=1,2, \ldots k$. The nonnegative assumption for $\ln w_{i} \geq 0(i=1,2, \ldots, k)$ is not essential. A negative value for $\lambda$ produced because there are no weights that can meet all the fuzzy judgments in $A$ within their support intervals. That is to say, not all the inequalities $\ln w_{i}-\ln w_{j}-\lambda \ln \left(m_{i j} / l_{i j}\right) \geq \ln l_{i j}$ or $-\ln w_{i}+\ln w_{j}-\lambda \ln \left(u_{i j} / m_{i j}\right) \geq-\ln u_{i j}$ can hold at the same time. To avoid $\lambda$ from taking a negative value, Wang, 2011 [18] introduced nonnegative deviation variables $\delta_{i j}$ and $\eta_{i j}$ for $i=1,2, \ldots, k-1$, and $j=i+1, \ldots, k$ such that they meet the following inequalities :

$$
\begin{aligned}
& \ln w_{i}-\ln w_{j}-\lambda \ln \left(\frac{m_{i j}}{l_{i j}}\right)+\delta_{i j} \geq \ln l_{i j}, i=1,2, \ldots, k-1 ; j=i+1, \ldots, k, \\
& -\ln w_{i}+\ln w_{j}-\lambda \ln \left(\frac{u_{i j}}{m_{i j}}\right)+\eta_{i j} \geq-\ln u_{i j}, i=1,2, \ldots, k-1 ; j=i+1, \ldots, k .
\end{aligned}
$$

The LFPP method formulated as

$$
\begin{gathered}
J=(1-\lambda)^{2}+P \sum_{i=1}^{k-1} \sum_{j=i+1}^{k}\left(\delta_{i j}^{2}+\eta_{i j}^{2}\right) \\
\text { Minimize } \\
\text { Subject to }\left\{\begin{array}{c}
x_{i}-x_{j}-\lambda \ln \left(m_{i j} / l_{i j}\right)+\delta_{i j} \geq \ln l_{i j}, i=1,2, \ldots, k-1, j=i+1, \ldots, k, \\
-x_{i}+x_{j}-\lambda \ln \left(u_{i j} / m_{i j}\right)+\eta_{i j} \geq-\ln u_{i j}, i=1,2, \ldots, k-1 ; j=i+1, \ldots, k, \\
\lambda, x_{i} \geq 0, i=1,2, \ldots, k, \\
\delta_{i j}, \eta_{i j} \geq 0, i=1,2, \ldots k-1, j=i+1, \ldots, k,
\end{array}\right.
\end{gathered}
$$

Let $x_{i}^{*}(i=1,2, \ldots, k)$ be the optimal solution to model. The normalized priorities for fuzzy pairwise comparison matrix $\tilde{A}=\left(\tilde{a}_{i j}\right)_{k x k}$ can be obtained as

$$
w_{i}^{*}=\frac{\exp \left(x_{i}^{*}\right)}{\left.\exp _{j=1}^{k} x_{j}^{*}\right)}, i=1,2, \ldots, k
$$

\section{RESULTS AND DISCUSSION}

This study is an experimental research involving website developer to evaluate websites. The alternative websites consists of five Indonesian university websites and their url address were : UGM (http://ugm.ac.id/), ITB (https://www.itb.ac.id/), UI (http://www.ui.ac.id/), UB (https://ub.ac.id/), and IPB (http://ipb.ac.id/). The data of the website quality was taken from 20 to 30 March 2017. The criteria of the website quality is taken though the web diagnostic tools http://alexa.com for page loading time, stickiness and backlink. The decided hierarchy for selecting the best university based on the quality of site can be seen in Figure 2. 


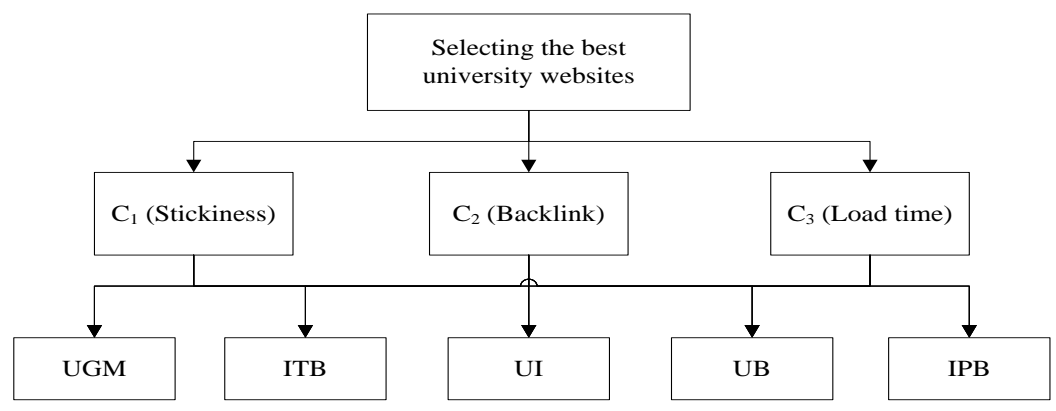

Figure 2. Hierarchical structure for university websites selection problem

Table 3 shows the pair wise comparison matrix for ranking university websites. The goal of this study to select the best university websites. There are three selection criteria, $\mathrm{C}_{1}$ (Stickiness), $\mathrm{C}_{2}$ (Backlink), and $\mathrm{C}_{3}$ (Load time).

Table 3. Fuzzy Pairwise Comparison Matrix of three selection Criteria

\begin{tabular}{cccc}
\hline Criteria & $C_{1}$ & $C_{2}$ & $C_{3}$ \\
\hline$C_{1}$ & $(1,1,1)$ & $(5,6,7)$ & $(1,2,3)$ \\
$C_{2}$ & $(1 / 7,1 / 6,1 / 5)$ & $(1,1,1)$ & $(1 / 4,1 / 3,1 / 2)$ \\
$C_{3}$ & $(1 / 3,1 / 2,1)$ & $(2,3,4)$ & $(1,1,1)$ \\
\hline
\end{tabular}

$$
\begin{aligned}
& \text { Minimize } J=(1-\lambda)^{2}+P \sum_{i=1}^{2} \sum_{j=i+1}^{3}\left(\delta_{i j}^{2}+\eta_{i j}^{2}\right) \\
& \text { Subject to }\left\{\begin{array}{c}
x_{1}-x_{2}-\lambda \ln (6 / 5)+\delta_{12} \geq \ln (5), \\
-x_{1}+x_{2}-\lambda \ln (7 / 6)+\eta_{12} \geq-\ln (7), \\
x_{1}-x_{3}-\lambda \ln (2)+\delta_{13} \geq \ln (1), \\
-x_{1}+x_{3}-\lambda \ln (3 / 2)+\eta_{13} \geq-\ln (3), \\
x_{2}-x_{3}-\lambda \ln (4 / 3)+\delta_{23} \geq \ln (1 / 4), \\
-x_{2}+x_{3}-\lambda \ln (3 / 2)+\eta_{23} \geq-\ln (1 / 2),
\end{array}\right.
\end{aligned}
$$

By solving model (13) for this fuzzy pairwise comparison matrix, we obtain the optimal solution as

$$
\begin{aligned}
& \lambda^{*}=0.999, \delta_{12}^{*}=-2.564 * 10^{-10}, \quad \eta_{12}^{*}=-2.859 * 10^{-10}, x_{1}=1.564, \\
& \delta_{13}^{*}=3.810^{*} 10^{-11}, \quad \eta_{13}^{*}=1.121 * 10^{-10}, x_{2}=-0.227, \\
& \delta_{23}^{*}=1.663 * 10^{-10}, \quad \eta_{23}^{*}=-9.421 * 10^{-11}, x_{3}=0.871 .
\end{aligned}
$$

Based on which, we have normalized LFPP priorities as

$$
\begin{aligned}
& w_{1}^{*}=\exp (1.564) /((\exp (1.564)+\exp (-0.227)+\exp (0.871))=0.6, \\
& w_{2}^{*}=\exp (-0.227) /((\exp (1.564)+\exp (-0.227)+\exp (0.871))=0.1, \\
& w_{3}^{*}=\exp (0.871) /((\exp (1.564)+\exp (-0.227)+\exp (0.871))=0.3,
\end{aligned}
$$


From the equation above, we produce $\lambda^{*}=0.999 \approx 1$, it means that this set of priority match fuzzy pairwise comparison matrix of three selection criteria in Table 3 has high consistency. Using the same way, the weighted assessment criteria pairwise comparisons between alternatives can calculated. Table 4 shows the data of quality criteria in five university websites. Measurement units for the criterion of load time and stickiness were second, and backlink was number.

Table 4. Original Data

\begin{tabular}{cccccc}
\hline Criteria & UGM & ITB & UI & UB & IPB \\
\hline $\mathrm{C}_{1}-$ Stickiness (second) & 256 & 268 & 346 & 272 & 268 \\
$\mathrm{C}_{2}-$ Backlink (number) & 8653 & 4758 & 6830 & 4415 \\
$\mathrm{C}_{3}$ - Load time (second) & 1.745 & 1.455 & 1.507 & 4954 & 1.535 \\
\hline
\end{tabular}

Table 5 shows the results of the normalized data measurement using Simple Additive Weighting (SAW) for five alternative websites in higher institution. SAW methods are used to generate the greatest value to be selected as the best alternative. This method requires the process of normalizing the matrix to a scale comparable to all current alternative ratings. The normalization results ranged from 0 to 1 .

Table 5. Normalized Data

\begin{tabular}{ccccccc}
\hline Criteria & UGM & ITB & UI & UB & IPB & Weight \\
\hline $\mathrm{C}_{1}$ & 0.833 & 1 & 0.965 & 0.947 & 0.817 & 0.6 \\
$\mathrm{C}_{2}$ & 0.739 & 0.774 & 1 & 0.786 & 0.774 & 0.1 \\
$\mathrm{C}_{3}$ & 1 & 0.549 & 0.789 & 0.510 & 0.572 & 0.3 \\
\hline
\end{tabular}

Table 6 shows multiplication of values by weights generates the aggregation of the local priorities and rank; the result represents that UI as the first rank and IPB as the fifth rank. The alternatives ranked as follow: $\mathrm{UI}>\mathrm{UGM}>\mathrm{ITB}>\mathrm{UB}>\mathrm{IPB}$.

Table 6. Aggregation of the local priorities

\begin{tabular}{llccccc}
\hline \multirow{2}{*}{ No } & \multirow{2}{*}{ Criteria } & UGM & ITB & University websites & UB & IPB \\
& & 0.4998 & 0.6000 & 0.5790 & 0.5682 & 0.4902 \\
1 & $\mathrm{C}_{1}$ & 0.0739 & 0.0774 & 0.1000 & 0.0786 \\
3 & $\mathrm{C}_{2}$ & 0.3000 & 0.1647 & 0.2367 & 0.0774 \\
Sum & $\mathrm{C}_{3}$ & 0.8737 & 0.8421 & 0.9157 & 0.1530 \\
Rank & & 2 & 3 & 1 & 0.7998 \\
\end{tabular}

\section{CONCLUSION}

The rank and performance of a university can be viewed from its academic activities on the internet that are reflected in the university website. Therefore, university website quality is important to show the credibility of a college. Based on the obtained data, it can be arranged that the site quality is ranked due to its stickiness, backlinks and load time by the LFPP method. The equation of model achieve high consistency of the set priority matching to fuzzy pairwise comparison matrix of three selection criteria. The results of this study show that stickiness is the most important factor that affects website's quality. For further study, criteria and alternatives to test whether the method works well can be added.

\section{REFERENCES}

[1] P. D. D. Dominic and S. Hanim, "University Website Quality Comparison by using Non-Parametric Statistical Test : A Case Study from Malaysia”, Int. J. Oper. Res., vol. 16, no. 3, pp. 349-374, 2013.

[2] M. J. Kargar, "University Website Ranking from Usability Criteria Perspective; A Case Study in IRAN", Int. J. Adv. Comput. Technol., vol. 3, no. 11, pp. 246-251, 2011.

[3] D. D. J. Suwawi, et al., "Evaluation of Academic Website using ISO/IEC 9126", Information and Communication Technology (ICoICT ), 2015 3rd International Conference on., pp. 222-227, 2015.

[4] I. F. Aguillo, et al., "Indicators for Webometrics Ranking of Open Access Repositories", Scienciometrics, vol. 82, no. 3, pp. 477-486, ST-Indicators for webometrics ranking o, 2010.

[5] H. Jati and a Webometrics, "Comparison of University Webometrics Ranking Using Multicriteria Decision Analysis : TOPSIS and VIKOR Method”, Word J. Int. Linguist. Assoc., pp. 1663-1669, 2012. 
[6] International Organization for Standardization, "Systems and Software Engineering -- Systems and Software Quality Requirements and Evaluation (SQuaRE) -- System and Software Quality Models", ISO/IEC, vol. 2011, p. 34, 2011.

[7] A. Fernandez, et al., "Integrating Usability Evaluation into Model-driven Video Game Development", Lecture Notes in Computer Science (including subseries Lecture Notes in Artificial Intelligence and Lecture Notes in Bioinformatics), vol. 7623, LNCS, ISSI Research Group, Department of Information Systems and Computation, Universitat Politècnica de València, Camí de Vera s/n, 46022, Valencia, Spain, pp. 307-314, 2012.

[8] A. Dix, et al., "Human-Computer Interaction", vol. Third, no. January. Scotprint, Haddington: Prentice Hall, 2004.

[9] H. Sharp, et al., "Interaction Design: Beyond Human-Computer Interaction", vol. 11. New York, USA: John Wiley \& Sons, Inc, 2002.

[10] N. E. Jacobsen, "Usability Evaluation Methods The Reliability and Usage of Cognitive Walkthrough and Usability Test", University of Copenhagen, Denmark, 1999.

[11] T. Wahyuningrum and K. Mustofa, "A Systematic Mapping Review of Software Quality Measurement: Research Trends, Model, and Method", Int. J. Electr. Comput. Eng., vol. 7, no. 5, p. 2847, 2017.

[12] Y. M. Wang and K. S. Chin, "A Linear Goal Programming Priority Method for Fuzzy Analytic Hierarchy Process and its Applications in new Product Screening", Int. J. Approx. Reason., vol. 49, no. 2, pp. 451-465, 2008.

[13] Y. M. Wang and K. S. Chin, "A Linear Programming Approximation to the Eigenvector Method in the Analytic Hierarchy Process”, Inf. Sci. (Ny)., vol. 181, no. 23, pp. 5240-5248, 2011.

[14] E. Ebrahimi, et al., "Applying Logarithmic Fuzzy Preference Programming and VIKOR for Ranking the Solutions of Knowledge Management Based on Critical Success Factors", World Appl. Program., vol. 4, no. 7, pp. 161-171, 2014.

[15] A. Sasani, et al., "Applying Logarithmic Fuzzy Preference Programming for Ranking of Effective Organizational Factors on Creativity: A Case Study Mansour Momeni Faculty of Management University of Tehran”, vol. 3, no. 14 , pp. 83-95, 2012.

[16] K. Mitra, "Validating AHP, Fuzzy Alpha cut and Fuzzy Preference Programming Method using Clustering Technique", Opsearch, vol. 47, no. 1, pp. 5-15, 2010.

[17] L. Mikhailov, "A Fuzzy Approach to Deriving Priorities from Interval Pairwise Comparison Judgements", Eur. J. Oper. Res., vol. 159, no. 3, pp. 687-704, 2004.

[18] Y. M. Wang and K. S. Chin, "Fuzzy Analytic Hierarchy Process: A Logarithmic Fuzzy Preference Programming Methodology", Int. J. Approx. Reason., vol. 52, no. 4, pp. 541-553, 2011.

[19] "uniRank Ranking Methodology", 2005. [Daring]. Tersedia pada: http://www.4icu.org/about/index.htm\#ranking. [Diakses: 18-Mei-2017].

[20] "Eduroute Top Ranking System", 2008. [Daring]. Tersedia pada: http://www.eduroute.info/University-RankingSystem.aspx. [Diakses: 18-Mei-2017].

[21] S. Nissom and N. Kulathuramaiyer, "The study of Webometrics Ranking of World Universities”, 2012.

[22] L. Björneborn and P. Ingwersen, "Perspective of Webometrics", Scientometrics, vol. 50, no. 1, pp. 65-82, 2001.

[23] P. D. D. Dominic and H. Jati, "A comparison of Asian Airlines Websites Quality: Using a Non-parametric Test Handaru Jati”, Int. J. Bus. Innov. Res., vol. 5, no. 5, 2011.

[24] M. A. Islam, "Webometrics study of Universities in Bangladesh", Ann. Libr. Inf. Stud., vol. 58, no. December, pp. 307-318, 2011.

[25] J. Nielsen, "Website Response Times", 2010. [Daring]. Tersedia pada: https://www.nngroup.com/articles/websiteresponse-times/. [Diakses: 05-Feb-2017].

[26] J. Nielsen, "Usability 101: Introduction to Usability", Nielsen Norman Group, 2012. [Daring]. Tersedia pada: https://www.nngroup.com/articles/usability-101-introduction-to-usability/.

[27] T. Albalushi, et al., "Accessibility and Performance Evaluation of E-Services in Oman Using Web Diagnostic Tools", Int. J. u-e-Serv. Sci. Technol., vol. 9, no. 7, pp. 9-24, 2016.

[28] T. L. Saaty, "How to make a decision: The Analytical Hierarchy Process", Eur. J. Oper. Res., vol. 48, pp. 9-26, 1990.

[29] M. Moayeri, et al., "Comparison of Fuzzy AHP and Fuzzy TOPSIS Methods for Math Teachers Selection”, Indian J. Sci. Technol., vol. 8, no. 13, 2015.

[30] K. K. Yuen dan H. C. Lau, "Evaluating Software Quality of Vendors using Fuzzy Analytic Hierarchy Process", in Proceedings of the International MultiConference of Engineers and Computer Scientists, 2008, vol. 1, pp. 19-21.

[31] M. B. Ayhan, "A Fuzzy AHP Approach for Supplier Selection Problem: A Case Study in a Gearmotor Company", Int. J. Manag. Value Supply Chain., vol. 4, no. 3, pp. 11-23, 2013.

[32] C. Sharma and S. K. Dubey, "Reliability Evaluation of Software System using AHP and Fuzzy TOPSIS Approach", Advances in Intelligent Systems and Computing, vol. 437, Amity School of Engineering and Technology, Amity University, Sec.-125, Noida, UP, India, pp. 81-92, 2016.

[33] M. Shaverdi, et al., "Application of Fuzzy AHP Approach for Financial Performance Evaluation of Iranian Petrochemical Sector”, Procedia Comput. Sci., vol. 31, no. Itqm, pp. 995-1004, 2014.

[34] F. Kong dan H. Liu, "Applying fuzzy analytic hierarchy process to evaluate success factors of e-commerce," Int. J. Inf. Syst. Sci., vol. 1, no. 3-4, hal. 406-412, 2005.

[35] Z. Turskis, E. K. Zavadskas, J. Antucheviciene, dan N. Kosareva, "A Hybrid Model Based on Fuzzy AHP and Fuzzy WASPAS for Construction Site Selection Methodology," Int. J. Comput. Commun. Control, vol. 10, no. 6, hal. 873-888, 2015.

[36] N.-F. Pan, "Fuzzy AHP Approach for Selecting the Suitable Bridge Construction Method", Autom. Constr., vol. 17, no. 8, pp. 958-965, 2008.

[37] D.-Y. Chang, "Applications of the Extent Analysis Method on Fuzzy AHP," Eur. J. Oper. Res., vol. 95, no. 3, 
pp. 649-655, 1996.

[38] B. D. Rouyendegh and T. E. Erkan, "Selection of Academic Staff using The Fuzzy Analytic Hierarchy Process (FAHP): A Pilot Study", Teh. Vjesn., vol. 19, no. 4, pp. 923-929, 2012.

[39] A. R. Afshari, et al., "Project Manager Selection by using Fuzzy Simple Additive Weighting Method", ICIMTR 2012 - 2012 Int. Conf. Innov. Manag. Technol. Res., pp. 412-416, 2012.

[40] C. C. Sun, "A Performance Evaluation Model by Integrating Fuzzy AHP and Fuzzy TOPSIS Methods", Expert Syst. Appl., vol. 37, no. 12, pp. 7745-7754, 2010.

[41] T. C. Wang and Y. H. Chen, "Applying Fuzzy Linguistic Preference Relations to the Improvement of Consistency of Fuzzy AHP”, Inf. Sci. (Ny)., vol. 178, no. 19, pp. 3755-3765, 2008.

\section{BIOGRAPHIES OF AUTHORS}
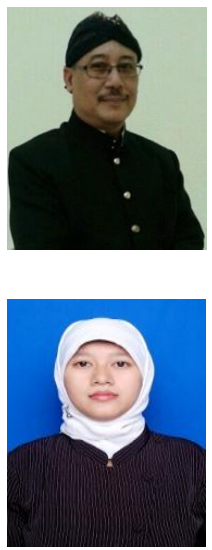

Retantyo Wardoyo, is a lecturer and a researcher at Department of Computer Science Universitas Gadjah Mada. He obtained his bachelor degree from Mathematics in Universitas Gadjah Mada, Indonesia (1982). He obtained his master degree from Computer Science in University of Manchester, UK (1990) and his doctoral degree from Computation in University of Manchester Institute of Sciences and Technology, UK (1996). His research interests include Intelligent Systems, Reasoning Systems, Expert Systems, Fuzzy Systems, Vision Systems, Group DSS \& Clinical DSS, Medical Computing \& Computational Intelligence.

Tenia Wahyuningrum, currently is pursuing her doctoral program in Department of Computer Science and Electronics, Faculty of Mathematics \& Natural Science, Universitas Gadjah Mada Yogyakarta, Indonesia. She took her undergraduate (S.Kom) at STMIK Widya Utama and Master (M.T) in Department of Electrical Engineering at Institut Teknologi Bandung in 2010. Her research areas of interest are Human Computer Interaction, Software Quality, and Software Engineering. 